\title{
Future of multiscale modelling of concrete - Toward a full integration of cement chemistry and concrete structural engineering
}

\author{
Tetsuya Ishida ${ }^{a^{*}}$, Tiao Wang ${ }^{\mathrm{a}}$ \\ a Department of Civil Engineering, School of Engineering, The University of Tokyo, 7-3-1 Hongo, Bunkyo-ku, Tokyo, \\ 113-8656, Japan
}

Received: 10 May 2018 / Accepted: 06 September 2018 / Published online: 17 September 2018

(C) The Author(s) 2018. This article is published with open access and licensed under a Creative Commons Attribution 4.0 International License.

\begin{abstract}
The use of supplementary cementitious materials (SCMs) to improve concrete performance has increased around the world in recent decades. Engineering practices demand a unified model for SCMs to predict and optimise the performance of blended-cement concrete. DuCOM-COM3 is a multi-chemophysical and multiscale analysis platform that can trace the whole-life behaviour and performance of reinforced concrete structures. However, the intrinsic heterogeneity and variability of SCMs present great challenges to the modelling of blended-cement concrete. This paper first reviews the challenges and difficulties of current models of blended-cement concrete. A multiphase modelling scheme based on DuCOM-COM3 analysis platform is introduced to consider different SCMs. Using the modelling scheme, a research road map for blended-cement concrete modelling is introduced for future study. It is hoped that the roadmap will help to reveal the mechanism of SCM reactions and their effect on concrete performance.
\end{abstract}

Keywords: SCMs; Multiphase modelling; Blended-cement concrete modelling; DuCOM-COM3

\section{Introduction}

Concrete is the most widely used construction material. It is estimated that the current global production of concrete is as much as 33 billion metric tonnes annually [1]. In practice, reinforced concrete (RC) structures undergo continuous deterioration due to combined environmental and loading actions from concrete mixing, such as thermal- or shrinkage induced cracking, fatigue due to repeated wheel loading, frost damage, chloride attack and alkali-silica reaction (ASR). A huge amount of money is spent every year to maintain existing RC structures, and this situation will continue in the future. For example, NEXCO (Nippon Expressway Company) estimates that more than 18 billion US dollars will be spent in the next 10 years just to maintain the RC slabs in the expressways in Japan. Engineering practices require a comprehensive analysis platform to predict the performance of RC structures. To meet this requirement, our research group has developed a multiscale, multi-chemo-physics analysis of structural concrete, called DuCOM-COM3. This multi-chemo-physical and mechanical platform is able to simulate cement hydration, micropore structure formation and mass transport in concrete to determine the mechanical behaviour of structural concrete from the millimetre to metre scales [2]. The integrated platform has been demonstrated to be able to track the whole-life behaviour and performance of
$\mathrm{RC}$ structures from the production and construction stages to the end of service life [3-5].

Engineers are also attempting to develop more durable concrete to reduce maintenance costs. Among the various measures being explored, the use of supplementary cementitious materials (SCMs) is one of the most promising. In addition to improving the workability of blended cement mixtures, SCMs also enhance the microstructure of cement and mitigate risks such as chloride attack and the ASR of blended-cement concrete. Studies $[1,6]$ have comprehensively summarised the advantages of SCMs, but their application is still hindered by their intrinsic and significant heterogeneity and variability [7-9]. More importantly, due to environmental protection concerns and transport costs, engineers must use local SCMs, even where their qualities are not stable, and handling in both the fresh and hardened states is difficult in practice. Proper mixture proportions and curing methods are needed to optimise the performance of blended-cement concrete [9]. Against this background, a multiphase modelling scheme that covers different SCMs coupled with DuCOM-COM3 was proposed [9] to predict the behaviour and optimise the performance of blended-cement concrete. Although some work has been done to characterise the material properties of SCMs and model their reaction in cement systems, current information

* Corresponding author: Tetsuya Ishida, Tel. +81 358417498, E-mail: tetsuya.ishida@civil.t.u-tokyo.ac.jp 
on the hydration products of SCMs is still insufficient to fully understand and model the behaviour of blended-cement concrete. This paper summarises the challenges in the modelling of blended-cement concrete and proposes a research roadmap for future study.

\section{Multiscale and multi-chemo-physics analysis platform DuCOM-COM3}

\subsection{Coupled analysis platform: DuCOM-COM3}

The coupled DuCOM-COM3 platform [10] is a multiscale analysis platform that links DuCOM [11] and COM3 [12]. DuCOM is a multi-chemo-physical platform that is able to simulate cement hydration, the latent hydration and pozzolanic reaction of various SCMs, micropore structure formation in cement paste and mass transport in concrete from nanometre to micrometre scale. COM3 is a threedimensional mesoscale platform used to simulate the mechanical behaviour of RC structures ranging from millimetre to metre scales, with in-depth consideration of time-dependent, cyclic and fatigue behaviour of concrete members [2]. By running a parallel thermodynamic analysis of DuCOM and COM3, the properties and structural responses of aging material can be predicted in a unified manner by the sharing of digital information.

Fig. 1 illustrates the overall computational scheme. The mix proportion, the characteristics of the binders and aggregate, the geometry of the target structure and the boundary conditions are first inputted into the DuCOM system [10, 11, 13]. The hydration and reaction of both cement and SCMs are then traced with a multicomponent heat generation model based on Arrhenius' law of chemical reaction. The microstructure of cement paste is obtained by modelling the average degree of hydration and the amount of chemically combined water in a micropore structure development model, with consideration of the physical characteristics of formed calcium silicate hydrate (C-S-H gel) $[10,11,13]$. The mechanical properties of aging concrete are then evaluated from the characteristics of the microstructure of cement paste, such as the porosity and pore size distribution. The moisture transport model, which accounts for vapour and liquid equilibrium and transport, yields the pore pressure, relative humidity and moisture distribution $[10,11,13]$. Creep and shrinkage are determined by the solidification theory and a rheological model based on the aforementioned computed thermo-hydraulic information $[10,11,13]$.

After running the thermo-hydraulic analysis, data on the strength, stiffness, temperature, water content and pore pressure are then stored in a common data area for use as essential parameters for the structural analysis by COM3. The degree of damage of structural concrete is then sent back to DuCOM for the next step, micro-thermodynamics analysis $[10,11,13]$. This coupling effect of the structural damage is taken into account by treating the cracks as newly created large-scale pores. The moisture and aggressive material transport are accordingly accelerated by additional cracking paths [14]. Therefore, DuCOM-COM3 is able to trace the lifespan performance of structural concrete [10, 11, 13]. As examples, two engineering applications of DuCOM-COM3 are introduced in the following sections.

\subsection{Early cracking assessment of RC bridge decks}

Much infrastructure was destroyed by the tsunami that followed the 2011 Great East Japan Earthquake, and the Japanese government resolved to build 'Revival Roads' to accelerate recovery. To enhance the durability of the RC bridge decks of these roads, multiple countermeasures have been proposed, including the use of a concrete mix with a low water-to-cement ratio and the use of SCMs. However, these high-durability specifications may conversely increase the risk of early age cracking caused by temperature and shrinkage due to the large amounts of cement required and the use of mineral admixtures [3].

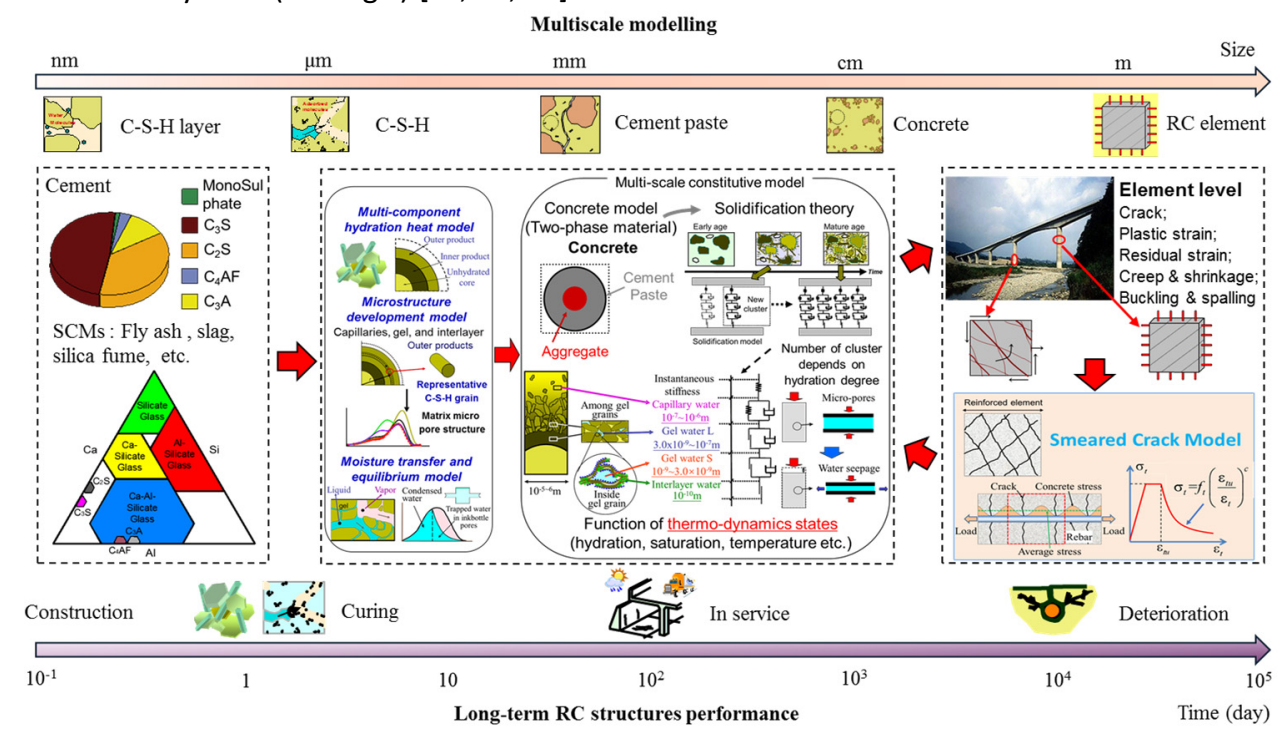

Figure 1. Multiscale simulation scheme of the whole-life performance of structural concrete. 


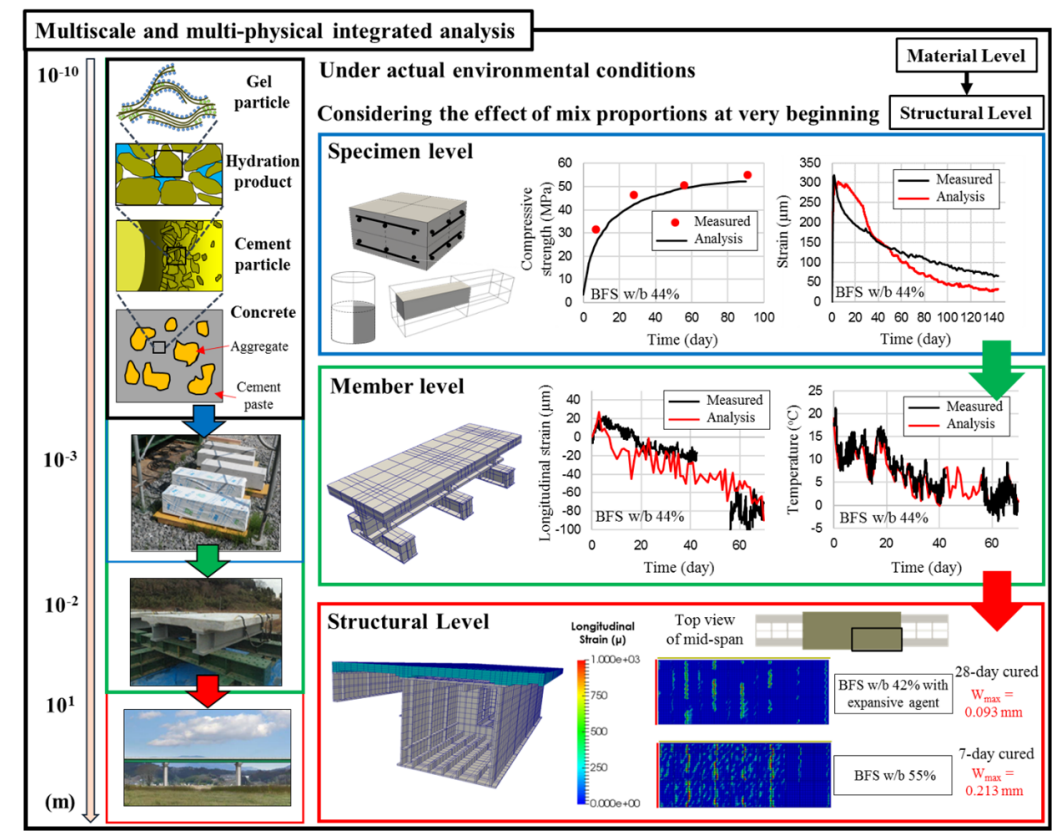

Figure 2. Early age cracking assessment of bridge deck slabs [3].

The early age deformation and cracking of an RC bridge deck was assessed with a full 3D multiscale and multi-chemophysical integrated analysis [3]. Fig. 2 presents a summary of the model validation and assessment scheme [3]. The multiscale thermodynamic integrated analysis was verified and validated at the laboratory scale in the order of decimetres up to the structural scale in the order of decametres, which adequately confirmed its ability to assess the behaviour of actual structures. Under real environmental conditions, various factors that affect the generation and propagation of cracks can be further identified and studied by numerical modelling. These analyses show that the coupled material-structure analysis scheme provides engineers with a powerful tool to evaluate and design mix proportions at the design stage.

\subsection{Excessive deflection of an existing bridge}

In-situ investigations have shown that many prestressed concrete bridges worldwide exhibit deflections in excess of predicted values [15]. DuCOM-COM3 was used to investigate the underlying mechanism of these excessive deflections exhibited by the Tsukiyono bridge (Fig. 3 (a) and (b)). The analysis results showed that the excessive deflections are rooted in the deformation of the cement paste due to both externally applied loads (case I in Fig. 3 (c)) and internal stresses driven by capillary surface tension and disjoining pressures in the micropores (case II in Fig. 3 (c)) [15]. By integrating thermodynamic and mechanistic analysis, the DuCOM-COM3 is capable of tracing excessive deflection (Fig. 3 (c)). The analysis results indicated that the long-term deflection of bridges can be approximately separated into deflections induced by external mechanistic action and deflection caused by internal thermodynamic action, which provides a practical measure to assess the long-term deflections of bridges in engineering practice. In conclusion, DuCOM-COM3 is capable of tracing the whole-life performance of RC structures and of providing practical guidance on construction and maintenance.

a
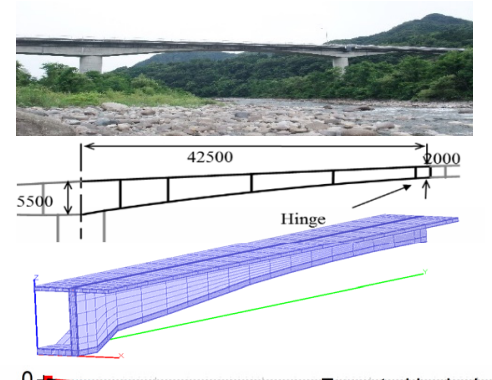

b
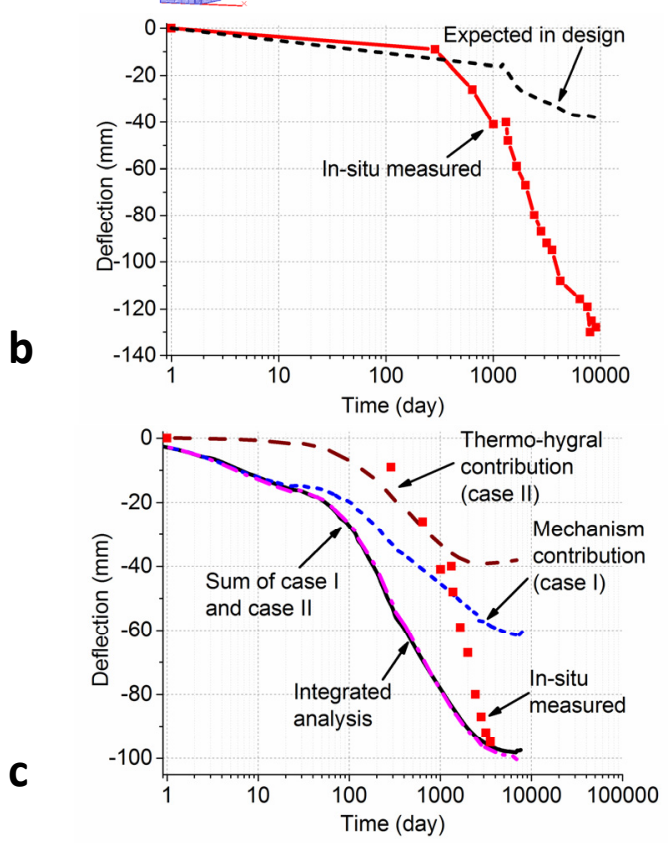

Figure 3. Excessive deflection of the Tsukiyono bridge predicted by the DuCOM-COM3 analysis platform [15]. (a) Bridge picture and model mesh; (b) Long-term deflection; (c) Analysis result. 


\section{Limitations of the current model for blended- cement concrete}

Although the coupled system DuCOM-COM3 has been satisfactorily applied to assess the whole-life performance of RC structures (see Fig. 2 and Fig. 3), the current model has several limitations in predicting the behaviour of blendedcement concrete. The following sections summarise these limitations.

\subsection{Variation in the material properties of SCMs}

Cement hydration and various SCM reactions in DuCOM are simulated by the multicomponent heat generation model. In this model, the total heat-generation rate of cementitious components $H_{c}$ is the sum of various cementitious components, including alite $\left(C_{3} S\right)$, belite $\left(C_{2} S\right)$, aluminate $\left(C_{3} A\right)$, ferrite $\left(C_{4} A F\right)$, blast-furnace slag $(B F S)$ and fly ash (see Eq. (1)).

$$
\begin{aligned}
H_{c}= & \sum p_{i} H_{i} \\
= & p_{C_{3} A}\left(H_{C_{3} A E T}+H_{C_{3} A}\right)+p_{C_{4} A F}\left(H_{C_{4} A F E T}+H_{C_{4} A F}\right) \\
& +p_{C_{3} S} H_{C_{3} S}+p_{C_{2} S} H_{C_{2} S}+p_{F A} H_{F A}+p_{\text {slag }} H_{\text {slag }}+\ldots
\end{aligned}
$$

where $H_{i}$ is the heat-generation rate of cement component $i$ per unit mass; $p_{i}$ is the mass fraction ratio of cement component $i$; and $H_{C_{3} A E T}$ and $H_{C_{4} A F E T}$ are the heat-generation rate of ettringite produced from aluminate $\left(C_{3} A\right)$ and ferrite $\left(\mathrm{C}_{4} \mathrm{AF}\right)$, respectively.

Because SCMs are the by-products of other production processes, they usually show significant heterogeneity and variability in material properties, even when they come from the same source. Durdziński showed that two types of highcalcium fly ash produced from the same power plant had different chemical components $[7,8,16]$. Because the current model traces SCMs through several individual phases, it cannot consider the variation in their material properties. Fig. 4 compares the predictions and experimental pozzolanic reaction degree of two Chinese commercial low-calcium fly ashes (Table. 1) with the same Blaine fineness of $6000 \mathrm{~cm}^{2} / \mathrm{g}$ in cement systems [17]. Fly ash FS has a higher pozzolanic reaction degree than $\mathrm{FSH}$, but the current model underestimates both and does not capture their differences.

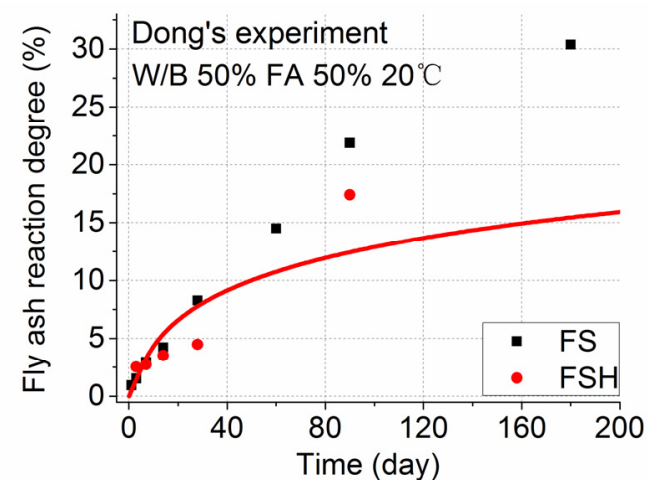

Figure 4. Comparison of the predictions of the current model and Dong's experiment [17].
Table 1 Material properties of fly ash FS and FSH

\begin{tabular}{|l|l|l|}
\hline & FS & FSH \\
\hline $\mathrm{SiO}_{2}$ (wt. \%) & 42.85 & 51.2 \\
\hline $\mathrm{Al}_{2} \mathrm{O}_{3}$ (wt. \%) & 41.26 & 30.3 \\
\hline $\mathrm{Fe}_{2} \mathrm{O}_{3}$ (wt. \%) & 4.32 & 4.53 \\
\hline $\mathrm{CaO}$ (wt. \%) & 3.89 & 5.49 \\
\hline $\mathrm{MgO}$ (wt. \%) & 0.56 & 0.81 \\
\hline $\mathrm{SO}_{3}$ (wt. \%) & 0.16 & 1.04 \\
\hline Density (g/cm ${ }^{3}$ ) & 2.15 & 2.23 \\
\hline $\mathrm{LOI}^{*}$ (\%) & 1.25 & 3.88 \\
\hline
\end{tabular}

* LOI is the loss of ignition of fly ash.

\subsection{Chloride ion transport of concrete made with SCMs}

SCMs can improve the durability performance of blendedcement concrete. For example, the substitution of SCMs such as fly ash and BFS cements can prevent the ingress of chloride ion into concrete [18-20]. Our research group compared the chloride resistance of various blended-cement mortars by salt-water immersion tests. Fig. 5 shows the experimental result for 2 years. Chloride can gradually migrate inside mortars made with ordinary Portland cement (OPC), even if the water-to-binder ratio is low $(\mathrm{W} / \mathrm{B}=20 \%)$ and the compressive strength is over $120 \mathrm{MPa}$. In contrast, the blended-cement mortars exhibit excellent resistance to chloride attack even with high water-to-binder ratio (W/B > 55\%) [21]. More interesting, the chloride migration seems to stagnate after 3 months regardless of replacement ratio when the $W / B$ is lower than $45 \%$. Similar results were also observed by Thomas et al. [22]. They studied chloride concentration profiles at different ages in fly ash concrete exposed in a marine tidal zone for up to 10 years. The chloride content barely increased at all beyond the initial 28-day period for the concrete with $30 \%$ fly ash [22]. W.Chalee et al. studied the rebar corrosion of fly ash concrete exposed to in hot marine conditions for 7 years. Experimental result showed that the utilization of fly ash dose be beneficial to suppress the rebar corrosion [23].

Recently, the chloride ion transport model has been enhanced by introducing the threshold pore radius of chloride ion transport and the water transport friction to consider the stagnation effect of chloride ions in low water-cement ratio cases with OPC [24]. However, this enhanced model still overestimates the extent of long-term chloride ingress for fly ash blended concrete (Fig. 6). Moreover, recent research has shown that different populations of chemical components in SCMs have a significant effect on blended-cement concrete performance. Durdziński demonstrated that two highcalcium fly ashes from the same power plant but with different chemical components had different effects on the pore size distribution and chloride resistance of blended cement paste [7]. This result suggests that the underlying mechanisms of chloride transport in blended-cement concrete have not yet been revealed. 

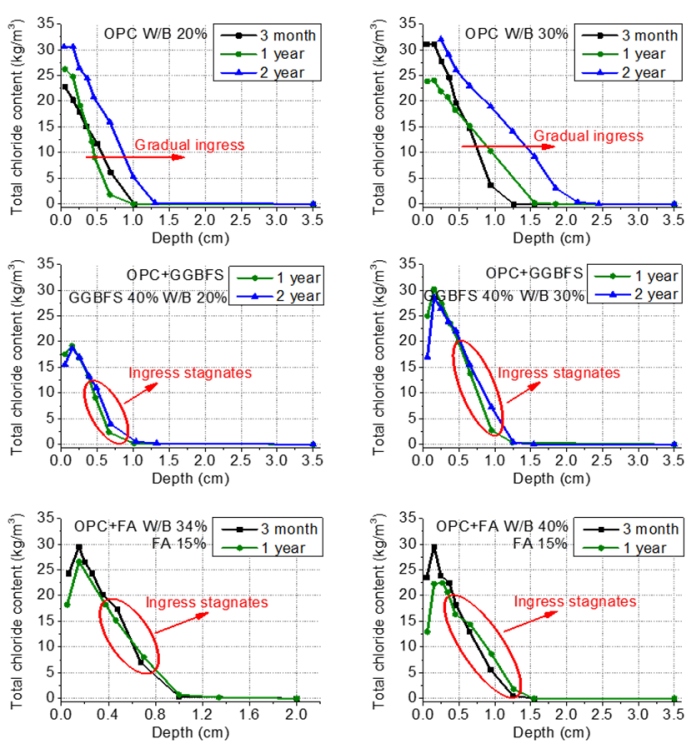

Figure 5
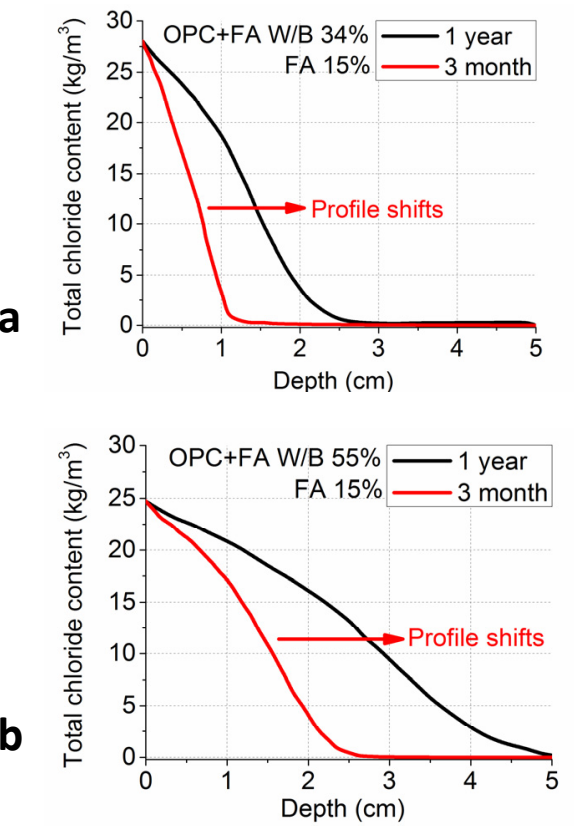

Figure 6. Numerical results for chloride ingression in fly ash blended mortars: (a) Water-binder ratio of $34 \%$; (b) Water-binder ratio of $55 \%$.

\subsection{Autogenous shrinkage of BFS concrete}

Although SCMs mitigate the risks of chloride attack and ASR, they may have some side effects on the durability of concrete. Our research group studied the autogenous shrinkage of different brands of commercially available BFS cements. The experimental results showed that BFS cements ( $45 \%$ cement clinkers replaced by BFS) have a higher autogenous shrinkage rate than OPC (Fig. 7) [25]. Moreover, different types of BFS cement exhibit different rates of shrinkage, with differences of almost twofold in cements that belong to the type $B$ cement of JIS 5211 [26]. These variations are believed to stem from the heterogeneity and variability of BFS material properties and their corresponding hydration products.
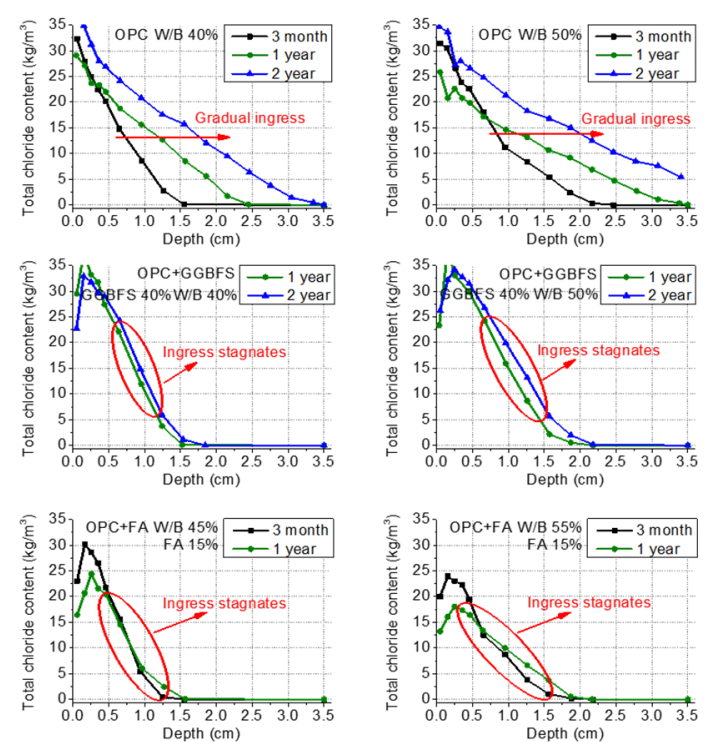

[21].

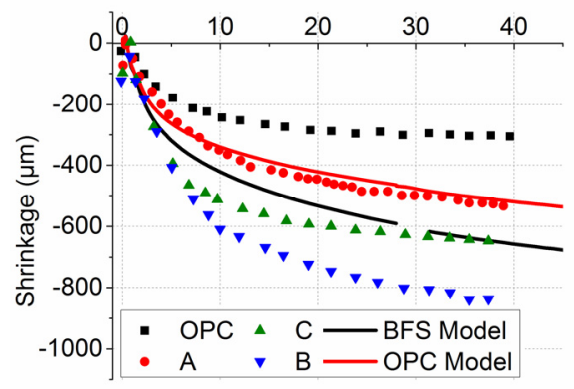

Figure 7. Comparison of autogenous shrinkage in BFS cement and OPC [25].

Again, because the material variations are not properly taken into account, the current model underestimates the autogenous shrinkage of BFS cement and does not capture differences (Fig. 7). In conclusion, it is important to study the variation in the material properties of SCMs and their effect on concrete performance to build a unified and comprehensive model.

\section{Multiphase reaction model of SCMs}

\subsection{Basic concept of a multiphase modelling scheme}

Although the mechanism of the performance variation in blended-cement concrete is not fully understood, it is generally believed that the variation in concrete performance stems from the heterogeneity and variability of the SCM material. Durdziński et al. $[7,8,16]$ did some pioneering work in characterising high-calcium fly ash with four different chemical glass components, i.e. silicate, Al-silicate, Ca-silicate and Ca-Al-silicate glass.

Based on Durdziński's work [7, 8, 16], a multiphase modelling scheme to cover different SCMs was proposed [9]. Compared to other models that focus on studying a material's specific parameters (e.g., fineness, water-binder ratio), this modelling scheme aims to distinguish and quantify material amounts through several basic phases of SCMs and to characterise 
their temperature-dependent kinetic properties [9]. Based on the multicomponent heat generation model (Eq. (1)), a more unified and comprehensive model (Eq. (2)) can be proposed to cover different types of SCMs that can also be easily extended to complicated mixtures that simultaneously use different SCMs [9].

$$
\begin{aligned}
H_{c}= & \sum p_{i} H_{i} \\
= & p_{C_{3} A}\left(H_{C_{3} A E T}+H_{C_{3} A}\right)+p_{C_{4} A F}\left(H_{C_{4} A F E T}+H_{C_{4} A F}\right) \\
& +p_{C_{3} S} H_{C_{3} S}+p_{C_{2} S} H_{C_{2} S}+p_{\text {Silicate }} H_{\text {Silicate }}+p_{A l-\text { silicate }} H_{A l-\text { silicate }} \\
& +p_{\text {Ca-silicate }} H_{C a-\text {-silicate }}+p_{\text {Ca-Al-silicate }} H_{C a-A l-\text { silicate }}
\end{aligned}
$$

Where $p_{\text {Silicate }}$ is the mass fraction ratio of the basic glass component silicate of SCMs; and $H_{\text {Silicate }}$ is the heatgeneration rate of the basic glass component silicate per unit mass. The definitions are similar for the other basic glasses such as Al-silicate, Ca-silicate and Ca-Al-silicate.

To implement this multiphase modelling scheme, three lowcalcium fly ashes with different reactivities were selected for study. The experimental results show that the reactive phases of low-calcium fly ash are composed mainly of silicate and Alsilicate glass; Al-silicate glass is more reactive than silicate glass but is less sensitive to temperature. The pozzolanic reactivity of fly ash depends on the amount of glass phase assemblage, the surface area and the intrinsic reactivity of the glass phase [9]. Two basic glass phases - silicate and Al-silicate glass - are incorporated into the multicomponent heat generation model. The glass-crystalline ratio is introduced to consider the intrinsic variation in glass. The numerical results show that the proposed model can be used to predict the time-dependent pozzolanic reaction of low-calcium fly ash [9] (Fig. 8).
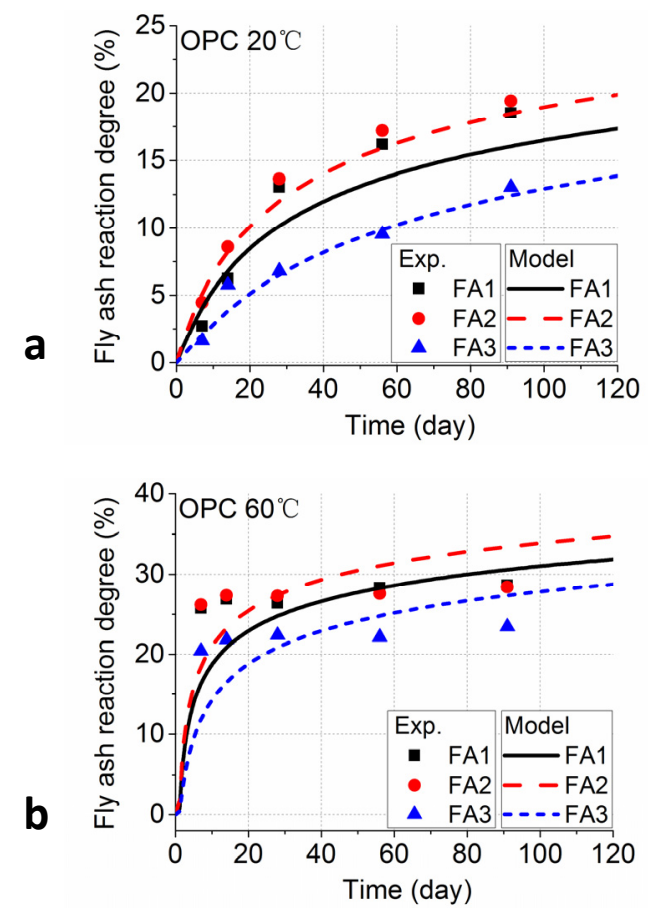

Figure 8. Comparison of fly ash reaction degrees from cement paste test results and current model simulations [9]: (a) OPC $20^{\circ} \mathrm{C}$; (b) OPC $60^{\circ} \mathrm{C}$.

\subsection{Future work on blended-cement concrete modelling}

Although some work has been done to implement the multiphase modelling scheme, it is still a long way from being able to model blended concrete. Some pioneering work has been done in recent decades. For example, Durdziński et al. characterized high-calcium fly ash with four different chemical glass components and experimentally confirmed that the intrinsic reactivities of these glasses are related to the number of non-bridging oxygens per tetrahedral networkforming ion (NBO/T) $[7,16]$. Wang recently found that, besides chemical effect, the intrinsic reactivities of glass phases also depends on their crystalline degree at the nanoscale [9]. In addition to characterising the material properties of SCMs, the corresponding hydration products of the basic glasses in cement systems should be more comprehensively investigated and studied, especially the special hydration products that occur in blended-cement concrete, such as low Ca-silicon ratio calcium silicate hydrate (low C/S C-S-H gel) and aluminium-modified calcium silicate hydrate (C-A-S-H gel). W. Casey et al. studied the leaching and reconstruction at nearsurface of chain-silicate minerals [27]. Richardson developed several models to describe C-A-S-H gel by comprehensively review previous experimental data [28]. Bauchy et al. studied fracture toughness and nano-ductility of aluminosilicate glasses [29] and tried to characterise and optimise cementitious binder's properties by topological approaches [30]. On the other hand, Nonat et al. found that the interaction of nano-C-S-H gel depends on $\mathrm{pH}$ and calcium concentration of pore solutions, which determines the morphology of precipitated C-S-H gel [31]. Ioannidou et al. subsequently confirmed this conclusion and studied these effects on mesoscale texture of cement hydration products by molecular dynamics [32]. Recently, Wang found that pozzolanic reaction would suppress cement hydration because the $\mathrm{C}-\mathrm{S}-\mathrm{H}$ gel more easily precipitated on cement particles as the continuous consumption of calcium hydroxide [9]. Although considerable effort has been made to characterise SCMs and their hydration productions of blended-cement concrete, the current information is still insufficient to construct a comprehensive and practical model to describe them and their effects on structural concrete mechanical performance. Therefore, this section provides a road map for future studies on this topic.

Fig. 9 schematically illustrates the road map. Various SCMs should first be comprehensively studied and characterised, including their amorphous and crystalline phase assemblage, specific surface area, thermal activation energy and intrinsic reactivity. In addition to silicate and Al-silicate glass, the highcalcium glasses Ca-silicate and Al-Ca-silicate must also be characterised for high-calcium SCMs, such as BFS and highcalcium fly ash. Based on this material characterisation, various basic glasses could be synthesised according to the real chemical components of the target SCMs. These synthesised glasses could be further studied in cement systems by preparing blended cement pastes under various curing conditions with different water-binder ratios and replacement ratios. The reaction degree of synthesised 
glasses can be measured by X-ray diffraction with the partial or no known crystal structure method or scanning electron microscopy (SEM)-energy dispersive X-ray spectroscopy (EDS) and image analysis. The chemical network and microstructures of the hydration products of the glass phases could be studied by advanced material characterisation methods, such as differential scanning calorimetry, nuclear magnetic resonance, small-angle X-ray scattering and transmission electron microscopy. The use of focused ion beam (FIB) SEM and nano-tomography was recently explored. This is a powerful technique for the determination and quantification of the three-dimensional microstructure of subsurface features (Fig. 10 (a)). The authors successfully obtained an SEM image that shows the microstructure formed by hydration products and pozzolanic reaction products around fly ash particles at the nano-scale (Fig. 10 (b)). Although this was a preliminary experimental study, we intend to study the characteristics of micro-pore structures for various types of SCMs.

A structural development model of the micropores in individual basic glasses could be developed for blendedcement concrete based on these experimental investigations. The concrete's mechanical properties could also be evaluated by applying the micropore structure to a micromechanical model. The information could then be validated by comparing the predictions of the model with experimental results on blended cement paste with the target SCMs. These material constitutive models should be verified and validated with small specimens by comparing meso-performance characteristics such as shrinkage, chloride ingression and water loss. Coupling effects, such as cracking and corrosion, could be further studied in a three-dimensional RC mechanical field. After verification, this multiphase modelling scheme could be applied to structural analysis platform (COM3) to finally assess the whole-life performance of RC structures.

\section{Conclusions}

SCMs are frequently used in the cement industry to improve the structural performance of RC. Engineering practices therefore require a unified model that considers various types of materials to predict and optimise the performance of blended-cement concrete and provide practical guidance on construction and maintenance. However, due to the intrinsic and significant heterogeneity and variability of SCMs, all current models face great challenges in the modelling of blended-cement concrete. This paper summarises the limitations of current models in modelling blended-cement concrete, including SCM reactions and durability performance. A multiphase modelling scheme based on DuCOM-COM3 analysis platform is introduced to cover the modelling of various types of blended-cement concrete. Finally, a research road map is proposed that includes material properties characterisation, small specimen verification and structural performance validation.

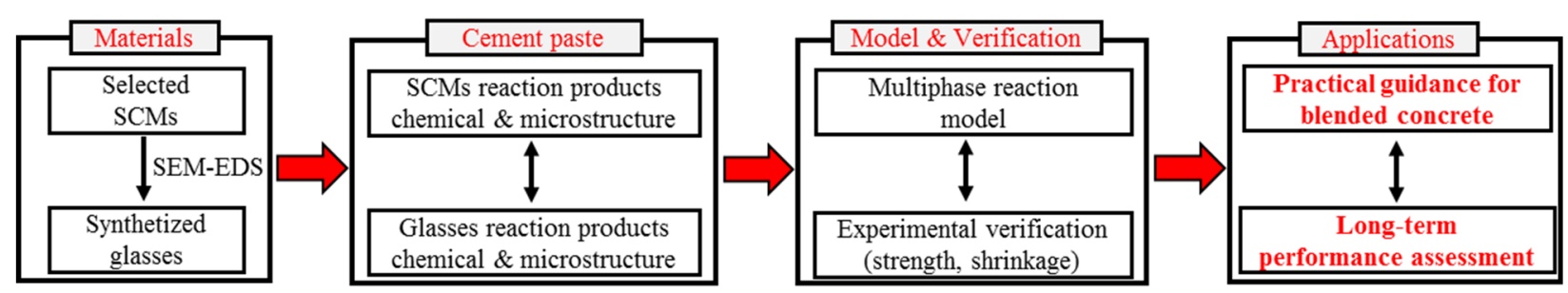

Figure 9. Future research scheme for blended-cement concrete modelling.

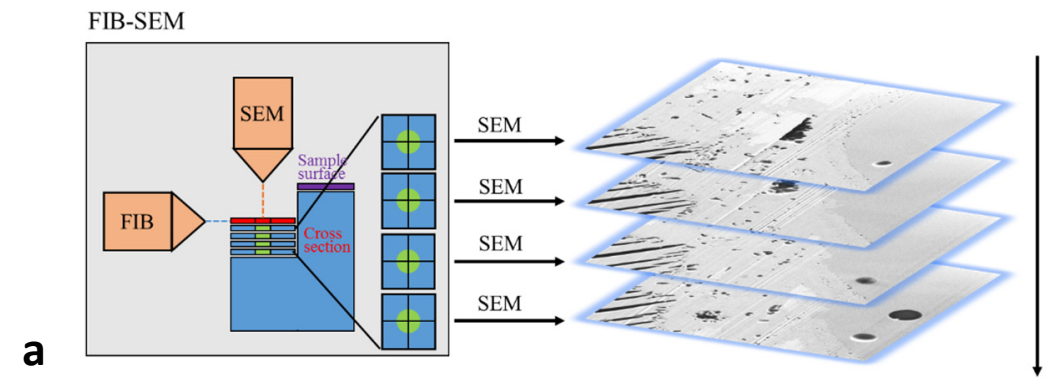

b

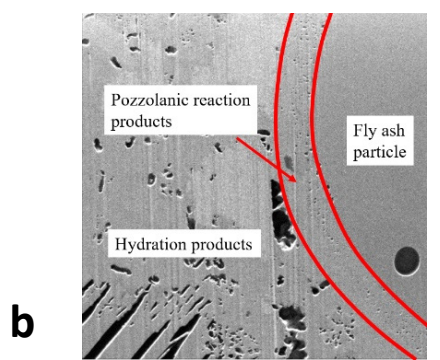

Figure 10. Three-dimensional reconstruction of the microstructure of fly ash cement paste. a) Illustration of the principle of three-dimensional reconstruction by FIB-SEM, b) SEM image of a cross-section implemented by FIB

\section{References}

[1] P.K. Mehta, P.J. Monteiro, Concrete: Microstructure, Properties, and Materials, Third ed., McGraw-Hill, New York, 2005.

[2] K. Maekawa, T. Ishida, N. Chijiwa, C. Fujiyama, Multiscale coupledhygromechanistic approach to the life-cycle performance assessment of structural concrete, J Mater Civ Eng (2013) 27 (2): A4014003. https://doi.org/10.1061/(ASCE)MT.1943-5533.0000984
[3] T. Ishida, K. Pen, Y. Tanaka, K. Kashimura, I. Iwaki, Numerical simulation of early age cracking of reinforced concrete bridge decks with a full-3d multiscale and multi-chemo-physical integrated analysis, Appl Sci (2018) 8 (3): 394 1-18.

[4] K. Maekawa, N. Chijiwa, T. Ishida, Long-term deformational simulation of PC bridges based on the thermo-hygro model of micro-pores in cementitious composites, Cem Concr Res (2011) 41(12): 1310-1319. https://doi.org/10.1016/j.cemconres.2011.03.021 
[5] K. Maekawa, X. Zhu, N. Chijiwa, S. Tanabe, Mechanism of long-term excessive deformation and delayed shear failure of underground RC box culverts, J Adv Concr Technol (2016) 14(5): 183-204. https://doi.org/10.3151/jact.14.183

[6] M.D.A. Thomas, Optimizing the use of fly ash in concrete, Portland Cem. Association Skokie, IL, 2007.

[7] P.T. Durdzinski, Hydration of multi-component cements containing cement clinker, slag, calcareous fly ash and limestone, Ph.D. thesis, EPFL, 2016.

[8] P.T. Durdziński, C.F. Dunant, M.B. Haha, K.L. Scrivener, A new quantification method based on SEM-EDS to assess fly ash composition and study the reaction of its individual components in hydrating cement paste, Cem Concr Res (2015) 73: 111-122. https://doi.org/10.1016/j.cemconres.2015.02.008

[9] T. Wang, Modeling of Pozzolanic reaction of siliceous fly ash in cement system based on its material characterization, PhD thesis, University of Tokyo, 2017.

[10] K. Maekawa, T. Ishida, T. Kishi, Multi-scale modeling of structural concrete, CRC Press, New York, 2008.

[11] K. Maekawa, R. Chaube, T. Kishi, Modelling of concrete performance: hydration, microstructure and mass transport, CRC Press, New York, 1999.

[12] K. Maekawa, H. Okamura, A. Pimanmas, Non-linear mechanics of reinforced concrete, CRC Press, New York, 2003.

[13] K. Maekawa, T. Ishida, Modeling of structural performances under coupled environmental and weather actions, Mater Struct (2002) 35(10): 591-602. https://doi.org/10.1007/BF02480352

[14] T. Ishida, P.O.N. Iqbal, H.T.L. Anh, Modeling of chloride diffusivity coupled with non-linear binding capacity in sound and cracked concrete, Cem. Concr. Res. (2009) 39(10): 913-923. https://doi.org/10.1016/j.cemconres.2009.07.014

[15] M. Ohno, N. Chijiwa, B. Suryanto, K. Maekawa, An investigation into the long-term excessive deflection of PC viaducts by using 3D multi-scale integrated analysis, J Adv Concr Technol (2012) 10 (2): 47-58. https://doi.org/10.3151/jact.10.47

[16] P.T. Durdziński, R. Snellings, C.F. Dunant, M.B. Haha, K.L. Scrivener, Fly ash as an assemblage of model $\mathrm{Ca}-\mathrm{Mg}-\mathrm{Na}$-Aluminosilicate glasses, Cem Concr Res (2015) 78 (B): 263-272.

[17] G. Dong, Reaction degree of fly ash and blast furnace slag in cement pastes (in Chinese), China Building. Material Academy, PhD thesis, 2008.

[18] K. Hossain, M. Lachemi, Corrosion resistance and chloride diffusivity of volcanic ash blended cement mortar, Cem Concr Res (2004) 34(4): 695 702. https://doi.org/10.1016/i.cemconres.2003.10.021

[19] A.K. Parande, B.R. Babu, M.A. Karthik, K.D. Kumaar, N. Palaniswamy, Study on strength and corrosion performance for steel embedded in metakaolin blended concrete/mortar, Constr Build Mater (2008) 22(3): 127-134. https://doi.org/10.1016/i.conbuildmat.2006.10.003

[20] A.R. Boğa, I.B. Topçu, Influence of fly ash on corrosion resistance and chloride ion permeability of concrete, Constr Build Mater (2012) 31: 258-264. https://doi.org/10.1016/j.conbuildmat.2011.12.106

[21] S. Koyanagi, Y. Takahashi, T. Ishida, An experimental study on material properties and time-dependent chloride diffusivity of cementitious materials mixed with GGBFS and fly ash, Proceedings of JCl, (2015) 37: 109-114.

[22] M.D.A. Thomas, J.D. Matthews, Performance of PFA concrete in a marine environment-10-year results, Cem Concr Compos (2004) 26 (1): 5-20. https://doi.org/10.1016/S0958-9465(02)00117-8

[23] W. Chalee, P. Ausapanit, C. Jaturapitakkul, Utilization of fly ash concrete in marine environment for long term design life analysis, Mater Design (2010) 31(3): 1242-1249. https://doi.org/10.1016/j.matdes.2009.09.024

[24] Y. Takahashi, T. Ishida, Modeling of chloride transport resistance in cement hydrates by focusing on nanopores, J Adv Concr Technol (2016) 14(11): 728-738. https://doi.org/10.3151/jact.14.728

[25] J.J. Ekaputri, T. Ishida, K. Maekawa, Autogeneous shrinkage of mortars made with different types of slag cement, JCl Annual Convention, Saitama, Japan, 2010.

[26] JIS, Standard R5211-2009: Portland blast-furnace slag cement (in Japanese), Japan Industrial Standard, Tokyo, 2009.

[27] W.H. Casey, H.R. Westrich, J.F. Banfield, G. Ferruzzi, G.W. Arnold, Leaching and reconstruction at the surfaces of dissolving chain-silicate minerals, Nature (1993) 366(6452): 253-256. https://doi.org/10.1038/366253a0

[28] I.G. Richardson, Model structures for C-(A)-S-H(I), Acta Crystallogr B Struct Sci Cryst Eng Mater (2014) 70 (6): 903-923. https://doi.org/10.1107/S2052520614021982
[29] M. Wang, B. Wang, T.K. Bechgaard, J.C. Mauro, S.J. Rzoska, M. Bockowski, M.M. Smedskjaer, M. Bauchy, Crucial effect of angular flexibility on the fracture toughness and nano-ductility of aluminosilicate glasses, J Non-Crystalline Solids (2016) 454: 46-51. https://doi.org/10.1016/j.jnoncrysol.2016.10.020

[30] H. Liu, T. Du, N.M.A. Krishnan, H. Li, M. Bauchy, Topological optimization of cementitious binders: advances and challenges, Cem Concr Compos (2018). https://doi.org/10.1016/j.cemconcomp.2018.08.002

[31] C. Plassard, E. Lesniewska, I. Pochard, A. Nonat, Nanoscale experimental investigation of particle interactions at the origin of the cohesion of cement, Langmuir (2005) 21(16): 7263-7270. https://doi.org/10.1021/la050440

[32] K. loannidou, K.J. Krakowiak, M. Bauchy, C.G. Hoover, E. Masoero, S. Yip, F.-J. Ulm, P. Levitz, R.J.-M. Pellenq, E. Del Gado, Mesoscale texture of cement hydrates, PANS (2016) 113(8): 2029-2034. https://doi.org/10.1073/pnas.1520487113 